\title{
Incidence of Anxiolytic/Hypnotic Therapy and Its Relationship to Duration of Antidepressant Therapy in a National Managed Care Organization
}

\begin{abstract}
OB.JECTIVE: To analyze the effects of concomitant anxiolytic/hypnotic use on duration of antidepressant therapy. The study was part of a national qualityimprovement initiative to understand current practices and improve the quality of care provided to patients by primary care physicians and psychiatrists.
\end{abstract}

DESIGN: A naturalistic, retrospective analysis using prescription, diagnosis, and eligibility databases.

SETTING: A national managed care organization (MCO) and its behavioral health subsidiary.

PATIENTS: 23,900 new patients who received benefits through a national MCO and initiated antidepressant therapy in mid-1995. The study population included adults who were continuously eligible for medical and pharmacy benefits during the study period and received at least one prescription for one of eight antidepressants between April 1, 1995 and August 31, 1995.

MAIN OUTCOME MEASURES: Concomitant anxiolytic and hypnotic use patterns were evaluated in the nine months following therapy initiation.

RESULTS: Patients with extended use of anxiolytics or hypnotics also had the longest duration of antidepressant therapy; patients with brief use of anxiolytics or hypnotics had the shortest duration of antidepressant therapy, regardless of prescriber type. Psychiatrists were more likely than primary care providers to prescribe concomitant anxiolytics/hypnotics and were more likely to prescribe antidepressants for longer duration of therapy across all categories of anxiolytic/hypnotic use.

CONCLUSIONS: As a result of these findings, interventions were targeted at educating primary care providers and psychiatrists about limiting the duration of concomitant anxiolytic/ hypnotic use and improving the understanding of depression and its relation to individual anxiety symptoms.

KEYWORDS: Depression treatment, anxiolytic use, hypnotic use, duration of therapy

J Managed Care Pharm 2000: 138-42

\section{Authors}

KAREN WAY, Ph.D., is a Team Leader and CHRISTOPHER YOUNG, Ph.D., is a Data Manager in the Research and Methodology Department at PCS Health Systems, Inc, in Scottsdale, AZ. DAVID WHITEHOUSE, M.D., M.B.A., is Corporate Medical Director in the Corporate Medical Department of MCC Behavioral Care in Eden Prairie, MN. At the time of the study, ELIZABETH OPLAND was Director of Corporate Medical at MCC Behavioral Care. TOM HUGHES, Ph.D., is a Research Scientist at Eli Lilly and $\mathrm{Co}_{\mathrm{o}}$ in Indianapolis, $\mathbb{N}$.

AUTHOR CORRESPONDENCE: Karn Way, Ph.D., Research and Methodology Department, PCS Health Systems, Inc., 9501 E. Shea Boulevard, MC 034, Scottsdalc, AZ 85260-6719; Tal: 602-661-3066; Fax: 602-3914525; E-mail: haren.way@pcshs.com.

ACKNOWLEDGMENTS: This study was supported financially by Eli Lilly and Company. At the time this research was conducted, PCS Health Systemts, inc., was a subsidiary of Eli Lilly and Company. The authors thank Annetle Fehr, M.B.A., for reviewing this manuscript.

Copyright(C 2000 Academy of Managed Care Pharmacy, Inc. All rights reserved.

by Karen Way, Christopher H. Young, Elizabeth Opland, David Whitehouse, and Tom Hughes

( ne of the greatest challenges to successfully treating depression is the fact that anxiety and sleep difficulties often accompany the illness. In fact, anxiety and sleep disorders may be the initial symptoms a patient reports-especially to a primary care physician-because they are easier to identify and carry less stigma. As a result, anxiolytic and hypnotic medications often comprise the first line of treatment. Problems can arise if these drugs then mask key depressive symptoms or inadequately treat the underlying depression. In addition, the prevalence of psychiatric comorbidity remains an important consideration; comorbid anxiety and depression have been portrayed as "so common that it is the rule, not the exception."

Physicians may have difficulty determining whether a patient has two primary comorbid disorders or has anxiety symptoms along with depression ("anxious depression"). Anxiety and depressive disorders share a number of overlapping features, including restlessness, malaise, sleep disturbance, appetite disturbance, impaired concentration, fatigue, irritability, and somatic complaints. Compared with those who have depression or anxiety alone, patients with concurrent anxiety and depression exhibit more psychopachology, are more chronically ill, show greater social and occupational impairment, display a higher probability of suicide, and have a poorer prognosis overall. ${ }^{2,3}$

Research on the relief of anxiety symptoms in depression treatment indicates that, in general, antidepressants should be used in treating anxiety or panic symptoms when depression is also present. Zajecka advocates antidepressant single-agent therapy as the best strategy to minimize side effects, simplify treatment, and optimize compliance, thereby minimizing the likelihood of early discontinuation of treatment. ${ }^{1}$

In addition, some evidence exists to show that benzodiazepines used in combination with an antidepressant can lead to a faster therapeutic effect in the treatment of depression and anxiety, particularly if benzodiazepines are used transitorily and tapered off slowly. ${ }^{2}$ However, Agency for Health Care Policy and Research (AHCPR) guidelines state that benzodiazepines have no proven efficacy in the treatment of depression, even in combination with antidepressants. The risk always exists that benzodiazepines may aggravate and worsen 


\section{Incidence of Anxiolytic/Hypnotic Therapy and Its Relationship to Duration of Antidepressant Therapy in a National Managed Care Organization}

a patient's depression, particularly with extended use.

Several classes of drugs are used to treat depression, including atypical antidepressants (AAs), such as bupropion, trazodone, and venlafaxine; selective serotonin reuptake inhibitors (SSRIs), such as fluoxetine, paroxetine, and sertraline; and tricyclic antidepressants (TCAs), such as amitriptyline and nortriptyline. Although clinical trial results indicate that all antidepressants may be equally efficacious for the treatment of depression, they are not necessarily equally effective based on their use in naturalistic settings. ${ }^{4.5}$ Zajecka cautions that TCAs have been efficacious in treating depressed patients with anxiety, but can be anxiogenic and carry risks for lethality in overdose. Anxiety also may be a common side effect of the shorter half-life SSRIs. ${ }^{1}$

\section{Methods}

\section{Background}

This study evaluated the effect of concomitant anxiolytic/hypnotic use on duration of antidepressant therapy among new antidepressant patients in 31 managed health care plans within a nationwide $\mathrm{MCO}$. This information was gathered as part of a quality-improvement initiative designed to improve utilization of antidepressants and the overall quality of care provided to depressed patients in partial fulfillment of National Committee for Quality Assurance (NCQA) accreditation. The initial qualityimprovement research and this study were collaborations among the pharmacy department of a national MCO, the medical department of the MCO's behavioral health subsidiary, and the Outcomes Research group at PCS Health Systems (PCS), a pharmacy benefits manager.

\section{Data}

Retrospective, longitudinal drug utilization analyses were conducted using the prescription, diagnosis (medical and psychiatric), and eligibility databases of the national MCO and its behavioral health subsidiary. The study evaluated clata recorded from January 1, 1995 through May 31, 1996.

\section{Patient Selection}

Adults who were continuously eligible for medical and pharmacy benefits at one of the 31 health plans and received at least one antidepressant prescription from April 1, 1995, through August 31, 1995 (the index period) were considered for selection. The antidepressants must have been provided as singleagent, oral, and solid dosage forms. The first antidepressant received during the index period was referred to as the index drug. The date of the first prescription for the index drug during the index period was referred to as the index date. Patients were excluded if they received: (1) more than one antidepressant on the index date; (2) an antidepressant in the three months prior to the index date; (3) an antidepressant prescription with a daily dose that exceeded $11 / 2$ the recommended maximum (to omit suspected data record errors); or (4) an antidepressant prescription that provided more than 100 days of therapy (to omit suspected data record errors). ${ }^{6}$ Patients were

\begin{tabular}{c|c}
\hline TABLE 1 Anxiolytic and Hypnotic Agents \\
Included in the Analyses
\end{tabular}

placed into comparison groups based on their index drug. For example, patients who initiated antidepressant therapy with amitriptyline were placed in the amitriptyline comparison group, whether or not they switched to another drug later in their course of therapy.

\section{Study Measures}

The demographic and other descriptive variables included in the analyses were sex, age, provider type (primary care provider or psychiatrist), diagnosis type, and geographic region. Provider type referred to the prescriber identified on the index prescription. Prescribers were classified as psychiatrists if they were identified as care providers in the behavioral health subsidiary of the MCO. All other prescribers were classified as primary care providers. A positive classification of a depression diagnosis required the presence of at least one recorded primary or secondary depression diagnosis during the study period. For patients with more than one type of depression diagnosis recorded, the diagnosis closest to the index date was used and the primary listing took precedence. Eight depression diagnoses were selected from the MCO primary care data, which used the coding scheme of the International Classification of Diseases, Ninth Revision (ICD-9). Six depression diagnoses were used from the behavioral health data, which used the coding scheme of the Diagnosis and Statistical Manual of Mental Disorders, Fourth Edition (DSM-IV). Patients were categorized as receiv- 


\begin{tabular}{|c|c|c|c|c|c|c|c|c|c|}
\hline & \multicolumn{9}{|c|}{ Index Drugs } \\
\hline & $\begin{array}{c}\text { Amitriptyline } \\
(\mathrm{n}=4,992)\end{array}$ & $\begin{array}{c}\text { Bupropion } \\
(\mathrm{n}=544)\end{array}$ & $\begin{array}{r}\text { Fluoxetine } \\
(n=6,259)\end{array}$ & $\begin{array}{c}\text { Nortriptyline } \\
(\mathrm{n}=1,555)\end{array}$ & $\begin{array}{l}\text { Paroxetine } \\
(n=3,012)\end{array}$ & $\begin{array}{l}\text { Sertraline } \\
(n=5,320)\end{array}$ & $\begin{array}{l}\text { Trazodone } \\
(\mathrm{n}=1,810)\end{array}$ & $\begin{array}{c}\text { Venlafaxine } \\
\qquad(n=408)\end{array}$ & $p$-value \\
\hline Gender (\% female) & $\begin{array}{l}72.4 \% \\
(3,615)\end{array}$ & $\begin{array}{l}58.3 \% \\
(317)\end{array}$ & $\begin{array}{l}73.8 \% \\
(4,621)\end{array}$ & $\begin{array}{l}71.3 \% \\
(1,108)\end{array}$ & $\begin{array}{l}71.2 \% \\
(2,144)\end{array}$ & $\begin{array}{c}71.9 \% \\
(3,826)\end{array}$ & $\begin{array}{c}66.8 \% \\
(1,209)\end{array}$ & $\begin{array}{c}67.9 \% \\
(277)\end{array}$ & $0.001^{1}$ \\
\hline Mean age $\pm S D$ & $45.7 \pm 13.2$ & $40.6 \pm 11.7$ & $41.1 \pm 11$ & $45.4 \pm 14.4$ & $42.8 \pm 12.5$ & $42.3 \pm 12.5$ & $47.0 \pm 13.9$ & $42.0 \pm 11.9$ & $0.0001^{2}$ \\
\hline $\begin{array}{l}\text { Provider type } \\
\text { Psychiatrist }\end{array}$ & $\begin{array}{l}1.2 \% \\
(58)\end{array}$ & $\begin{array}{l}40.8 \% \\
(222)\end{array}$ & $\begin{array}{l}20.8 \% \\
(1,301)\end{array}$ & $\begin{array}{l}6.5 \% \\
(101)\end{array}$ & $\begin{array}{l}17.8 \% \\
(537)\end{array}$ & $\begin{array}{c}20.1 \% \\
(1,067)\end{array}$ & $\begin{array}{l}12.1 \% \\
(219)\end{array}$ & $\begin{array}{l}27.2 \% \\
(111)\end{array}$ & $0.001^{1}$ \\
\hline $\begin{array}{c}\text { Primary care } \\
\text { Provider }\end{array}$ & $\begin{array}{c}98.8 \% \\
(4,934)\end{array}$ & $\begin{array}{l}59.2 \% \\
(322)\end{array}$ & $\begin{array}{l}79.2 \% \\
(4,958)\end{array}$ & $\begin{array}{l}93.5 \% \\
(1,454)\end{array}$ & $\begin{array}{l}82.2 \% \\
(2,475)\end{array}$ & $\begin{array}{c}79.9 \% \\
(4,253)\end{array}$ & $\begin{array}{l}87.9 \% \\
(1,591)\end{array}$ & $\begin{array}{l}72.8 \% \\
(297)\end{array}$ & \\
\hline $\begin{array}{l}\text { Specific depression } \\
\text { diagnosis }(\%)\end{array}$ & $\begin{array}{l}6.6 \% \\
(328)\end{array}$ & $\begin{array}{l}31.2 \% \\
(1.74)\end{array}$ & $\begin{array}{l}26.9 \% \\
(1683)\end{array}$ & $\begin{array}{l}10.9 \% \\
(169)\end{array}$ & $\begin{array}{l}24.9 \% \\
(749)\end{array}$ & $\begin{array}{l}27.0 \% \\
(1435)\end{array}$ & $\begin{array}{l}16.9 \% \\
(306)\end{array}$ & $\begin{array}{l}28.2 \% \\
(115)\end{array}$ & \\
\hline $\begin{array}{l}\text { Nonspecific } \\
\text { depression diagnosis } \\
\text { (311) (\%) }\end{array}$ & $\begin{array}{l}3.7 \% \\
(185)\end{array}$ & $\begin{array}{c}11.6 \% \\
(63)\end{array}$ & $\begin{array}{l}15.3 \% \\
(957)\end{array}$ & $\begin{array}{l}5.9 \% \\
(92)\end{array}$ & $\begin{array}{l}15.5 \% \\
(466)\end{array}$ & $\begin{array}{l}15.3 \% \\
(816)\end{array}$ & $\begin{array}{l}8.5 \% \\
(153)\end{array}$ & $\begin{array}{l}11.3 \% \\
(46)\end{array}$ & $0.001^{1}$ \\
\hline $\begin{array}{l}\text { No depression } \\
\text { diagnosis }(\%)\end{array}$ & $\begin{array}{l}89.7 \% \\
(4,479)\end{array}$ & $\begin{array}{l}56.4 \% \\
(307)\end{array}$ & $\begin{array}{l}57.8 \% \\
(3,619)\end{array}$ & $\begin{array}{l}83.2 \% \\
(1,292)\end{array}$ & $\begin{array}{l}59.7 \% \\
(1,797)\end{array}$ & $\begin{array}{l}57.7 \% \\
(3,069)\end{array}$ & $\begin{array}{l}74.6 \% \\
(1,351)\end{array}$ & $\begin{array}{l}60.5 \% \\
(247)\end{array}$ & \\
\hline Geographic region & & & & & & & & & \\
\hline North Central & $15.7 \%$ & $3.0 \%$ & $32.6 \%$ & $6.0 \%$ & $12.6 \%$ & $23.4 \%$ & $5.0 \%$ & $1.9 \%$ & \\
\hline Northeast & 15.4 & 2.2 & 31.0 & 7.0 & 12.0 & 25.9 & 3.5 & 3.2 & \\
\hline Mid Atlantic & 16.0 & 2.9 & 28.2 & 6.6 & 16.1 & 24.8 & 3.7 & 1.8 & \\
\hline Midwest & 15.3 & 1.2 & 24.1 & 5.6 & 15.3 & 29.9 & 7.2 & 1.6 & $0.001^{1}$ \\
\hline South Central & 19.1 & 2.0 & 27.8 & 6.3 & 15.0 & 20.1 & 7.7 & 2.1 & \\
\hline Southeast & 18.3 & 2.1 & 28.0 & 5.6 & 12.8 & 26.1 & 6.1 & 1.0 & \\
\hline Southwest & 23.6 & 2.3 & 22.0 & 8.0 & 12.1 & 20.5 & 9.6 & 1.9 & \\
\hline West & 25.3 & 2.5 & 27.9 & 5.0 & 10.7 & 18.8 & 8.5 & 1.3 & \\
\hline
\end{tabular}

${ }^{1}$ Chi-square test at the 0.05 level of significance. ${ }^{2}$ ANOVA at the 0.05 level of significance

ing: (1) a nonspecific depression diagnosis (coded as 311 in both diagnostic schemes); (2) a specific depression diagnosis (depression diagnoses other than 311); or (3) no depression diagnosis.

Concomitant anxiolytic/hypnotic use was evaluated before and after antidepressant therapy began. The anxiolytic and hypnotic medications included in the analyses are listed in Table 1. Anxiolytic/hypnotic use in the nine months following initiation of therapy was categorized by duration of concomitant therapy: (1) brief: 30 days or fewer of concomitant anxiolytic/hypnotic use in the post period; (2) extended: 31 days or more of concomitant anxiolytichypnotic use in the post period; or (3) none: no concomitant anxiolytic/hypnotic use in the post period. Anxiolytic/hypnotic use in the prior period was defined as the receipt of at least one anxiolytic/hypnotic prescription in the three months prior to therapy initiation.

Duration of therapy was measured by days of continuous index drug therapy, defined as having no more than a 30-day gap between the last day of therapy with one index drug prescription and the fill date for the subsequent index drug prescription.

\section{Analysis}

The chi-square test was used to test differences among index drug comparison groups for: sex, provider type, diagnosis type, and geographic region. Mean age differences and mean days of continuous therapy among the study drug comparison groups were tested using analysis of variance (ANOVA).

Multivariate analyses were conducted to explore the relationships among index drugs, categories of concomitant anxiolytic/hypnotic use (brief, extended, or none), and prescriber type. Likelihood ratio chi-squares $\left(G^{2}\right)$ are reported for these analyses.

\section{Limitations}

Selection issues that may affect the results reported here are important considerations. The findings described are intended to explain how antidepressants were utilized rather than why they were utilized as they were. The causes of observed antidepressant utilization characteristics are multidimensional, reflecting a combination of factors including the patient, prescriber, and medication.

Moreover, the retrospective claims data used in this study 
Incidence of Anxiolytic/Hypnotic Therapy and Its Relationship to Duration of Antidepressant Therapy in a National Managed Care Organization

TABLE 3 Duration of Concomitant Anxiolytic/Hypnotic Use by Index Drug and Prescriber Type $(n=23,900)$

\begin{tabular}{|c|c|c|c|c|c|c|c|c|c|c|}
\hline & \multicolumn{10}{|c|}{ Index Drugs } \\
\hline & $\begin{array}{l}\text { Amitriptyline } \\
(\mathrm{n}=4,992)\end{array}$ & $\begin{array}{c}\text { Bupropion } \\
(n=544)\end{array}$ & $\begin{array}{l}\text { Fluoxetine } \\
(n=6,259)\end{array}$ & $\begin{array}{l}\text { Nortriptyline } \\
\qquad(n=1,555)\end{array}$ & $\begin{array}{l}\text { Paroxetine } \\
(n=3,012)\end{array}$ & $\begin{array}{l}\text { Sertraline } \\
(n=5,320)\end{array}$ & $\begin{array}{l}\text { Trazodone } \\
(n=1,810)\end{array}$ & $\begin{array}{l}\text { Venlafaxine } \\
\qquad(n=408)\end{array}$ & $\begin{array}{l}\text { Overall } \\
(23,900)\end{array}$ & $p$-value \\
\hline Brief ( $\leq 30$ days) & & & & & & & & & & \\
\hline Psychiatrist & $\begin{array}{c}8.6 \% \\
(5)\end{array}$ & $\begin{array}{l}19.8 \% \\
(44)\end{array}$ & $\begin{array}{l}13.8 \% \\
(179)\end{array}$ & $\begin{array}{c}23.8 \% \\
(24)\end{array}$ & $\begin{array}{l}15.8 \% \\
(85)\end{array}$ & $\begin{array}{l}17.2 \% \\
(184)\end{array}$ & $\begin{array}{l}11.9 \% \\
(26)\end{array}$ & $\begin{array}{c}16.2 \% \\
(18)\end{array}$ & $\begin{array}{l}15.6 \% \\
(565)\end{array}$ & $0.001^{1}$ \\
\hline $\begin{array}{l}\text { Primary care } \\
\text { Provider }\end{array}$ & $\begin{array}{l}12.9 \% \\
(637)\end{array}$ & $\begin{array}{c}12.4 \% \\
(40)\end{array}$ & $\begin{array}{r}12.0 \% \\
(594)\end{array}$ & $\begin{array}{l}12.5 \% \\
(182)\end{array}$ & $\begin{array}{l}15.2 \% \\
(376)\end{array}$ & $\begin{array}{l}12.7 \% \\
(538)\end{array}$ & $\begin{array}{l}14.8 \% \\
(235)\end{array}$ & $\begin{array}{c}13.5 \% \\
(40)\end{array}$ & $\begin{array}{l}13.0 \% \\
(2,642)\end{array}$ & \\
\hline Extended ( $\geq 31$ days) & & & & & & & & & & \\
\hline Psychiatrist & $\begin{array}{c}24.1 \% \\
(14)\end{array}$ & $\begin{array}{c}23.9 \% \\
(53)\end{array}$ & $\begin{array}{l}17.8 \% \\
(231)\end{array}$ & $\begin{array}{c}19.8 \% \\
(20)\end{array}$ & $\begin{array}{c}24.4 \% \\
(131)\end{array}$ & $\begin{array}{l}19.1 \% \\
(204)\end{array}$ & $\begin{array}{c}28.3 \% \\
(62)\end{array}$ & $\begin{array}{c}18.9 \% \\
(21)\end{array}$ & $\begin{array}{c}20.4 \% \\
(736)\end{array}$ & $0.001^{1}$ \\
\hline $\begin{array}{l}\text { Primary care } \\
\text { Provider }\end{array}$ & $\begin{array}{l}11.3 \% \\
(556)\end{array}$ & $\begin{array}{c}14.9 \% \\
(48)\end{array}$ & $\begin{array}{l}13.6 \% \\
(672)\end{array}$ & $\begin{array}{l}14.5 \% \\
(211)\end{array}$ & $\begin{array}{l}14.7 \% \\
(363)\end{array}$ & $\begin{array}{l}14.3 \% \\
(606)\end{array}$ & $\begin{array}{l}16.2 \% \\
(258)\end{array}$ & $\begin{array}{c}17.5 \% \\
(52)\end{array}$ & $\begin{array}{l}13.6 \% \\
(2,766)\end{array}$ & \\
\hline $\begin{array}{c}\text { No Concomitant } \\
\text { Use }\end{array}$ & & & & & & & & & & \\
\hline Psychiatrist & $\begin{array}{c}67.2 \% \\
(39)\end{array}$ & $\begin{array}{l}56.3 \% \\
(125)\end{array}$ & $\begin{array}{l}68.5 \% \\
(891)\end{array}$ & $\begin{array}{c}56.4 \% \\
(57)\end{array}$ & $\begin{array}{l}59.8 \% \\
(321)\end{array}$ & $\begin{array}{l}63.6 \% \\
(679)\end{array}$ & $\begin{array}{c}59.8 \% \\
(131)\end{array}$ & $\begin{array}{c}64.9 \% \\
(72)\end{array}$ & $\begin{array}{c}64.0 \% \\
(2,315)\end{array}$ & $0.001^{1}$ \\
\hline $\begin{array}{c}\text { Primary care } \\
\text { Provider }\end{array}$ & $\begin{array}{c}75.8 \% \\
(3,741)\end{array}$ & $\begin{array}{c}72.7 \% \\
(234)\end{array}$ & $\begin{array}{c}74.5 \% \\
(3.692)\end{array}$ & $\begin{array}{c}73.0 \% \\
(1,061)\end{array}$ & $\begin{array}{c}70.1 \% \\
(1,736)\end{array}$ & $\begin{array}{c}73.1 \% \\
(3,109)\end{array}$ & $\begin{array}{c}69.0 \% \\
(1,098)\end{array}$ & $\begin{array}{c}69.0 \% \\
(205)\end{array}$ & $\begin{array}{c}73.3 \% \\
(14,876)\end{array}$ & \\
\hline
\end{tabular}

'Chi-square test at the 0.05 level of significance

were not intended for research. For a variety of reasons, including coding errors and/or depression misdiagnoses (deliberate or otherwise), information contained in the administrative data may not accurately reflect each diagnosis, or the actual care that was provided. Thus, references in this report to patients with or without depression diagnoses actually reflect whether such diagnoses were recorded as primary or secondary diagnoses on the medical claim.

Finally, the retrospective study design precluded randomization of patients. Without randomization, the findings presented in this report are more likely to have been influenced by extraneous factors, such as severity of depression, comorbidities, and physician or patient characteristics.

\section{Results}

On average, 2,686,587 enrollees per month were eligible for pharmacy and medical benefits in the 31 health plans during the study period. A total of 26,836 patients met the a priori selection criteria, $89 \%$ of whom initiated therapy with one of eight of the drugs studied: amitriptyline, bupropion, fluoxetine, nortriptyline, paroxetine, sertraline, trazodone, and venlafaxine. Only patients who initiated therapy with these eight antidepressants were actually included in the study $(n=23,900)$.

\section{Demographics}

Table 2 presents demographics and information on other descriptive variables by study drug. The major findings follow.

Sex distribution differences among the drug comparison groups were statistically significant $(p \leq 0.001)$, with females comprising $71.6 \%$ of the study patients. A significantly ( $p \leq$ 0.05 ) smaller percentage of females was prescribed bupropion when compared to all other study drugs except venlafaxine.

The mean age of study patients was $43.3 \pm 12.7$. Mean age differences were statistically significant $(p \leq 0.0001)$ among study drugs; however, the low $\mathrm{R}^{2}$ of 0.026 indicates that the statistical significance is likely due to the sample size.

Psychiatrists initiated index drug therapy for $15.1 \%$ of the study patients and were significantly $(p \leq 0.001$ ) more likely to prescribe fluoxetine or sertraline over all other study drugs. Primary care doctors were significantly $(p \leq 0.001)$ more likely to prescribe fluoxetine or amitriptyline over all other study drugs.

Overall, a specific diagnosis of depression was recorded for $20.7 \%$ of the study patients; $67.6 \%$ did not receive a recorded depression diagnosis. Bupropion and venlafaxine were most frequently prescribed for patients with specific diagnoses recorded on their claims; TCAs were most frequently prescribed for patients without recorded depression diagnoses.

The overall geographic distribution of the study patients was: North Central, 5.4\%; Northeast, 5.8\%; Mid Atlantic, 5.5\%; Midwest, 5.1\%; South Central, 9.3\%; Southeast, 16.4\%; Southwest, $33.5 \%$; and West, $19.0 \%$. Geographic distribution differences among the drug comparison groups were statistically significant $(p \leq 0.001)$, reflecting the higher concentration of prescribers in the Southwest and West. The row percentage findings indicate that fluoxetine and sertraline were most frequently prescribed overall, regardless of geographic region. 


\section{Incidence of Anxiolytic/Hypnotic Therapy and Its Relationship to Duration of Antidepressant Therapy in a National Managed Care Organization}

\section{Duration of Concomitant Anxiolytic/Hypnotic Use}

Table 3 reports the duration of concomitant anxiolytic/hypnotic use (brief $[\leq 30$ days], extended [ $\geq 31$ days], or no concomitant use) by index drug and prescriber type. The proportion of patients with brief duration of concomitant anxiolytic/hypnotic therapy was highest among patients who were prescribed bupropion or nortriptyline as their index antidepressant by psychiatrists. The proportion of patients with extended anxiolytic/hypnotic use was highest among patients who were prescribed trazodone, paroxetine, or bupropion by psychiatrists. Primary care prescribers were the least likely to prescribe concurrent anxiolytics or hypnotics. Overall, pairwise comparisons by study drug and prescriber type found significant $(p \leq 0.0108)$ differences in concomitant anxiolytic/hypnotic use for patients initiating therapy on all index drugs except venlafaxine.

Patients with extended use of anxiolytics/hypnotics in the post period had the longest duration of therapy $(100.7 \pm 70.0$ days for psychiatrist prescribers, and $87.5 \pm 70.3$ days for primary care prescribers). Patients with brief anxiolytic/hypnotic use had the shortest duration of therapy $(82.4 \pm 64.1$ days for psychiatrist prescribers, and $67.7 \pm 59.7$ days for primary care prescribers). These relationships held true regardless of prescriber type.

\section{Discussion}

In the preliminary phase of this project, we analyzed only patients with depression diagnoses and found that $58.2 \%$ of patients who used an anxiolytic or hypnotic in the three-month prior period had extended concomitant use of anxiolytics/hypnotics in the nine-month post period. By contrast, only $11.3 \%$ of those patients with no prior use had extended anxiolytic/hypnotic use in the post period. This finding suggests that when depressed patients begin therapy on an anxiolytic/hypnotic rather than an antidepressant, they may be at greater risk for extended anxiolytic/hypnotic use. Such findings might indicate that prescribers focused on symptom-resolution rather than on a holistic understanding of the entire clinical picture for patients who are multisymptomatic and perhaps even more vulnerable to the depressogenic effects of anxiolytics.

In a previous collaborative study, we found that lack of a recorded depression diagnosis proved to be one indicator of poor quality of care. ${ }^{7}$ Therefore in this sludy we wanted to include patients without recorded depression diagnoses. Our analysis of all patients found that the same relationships held for depression-diagnosed patients only-that is, patients with prior use of either an anxiolytic or a hypnotic were more likely to have extended anxiolytic/hypnotic use in the post period, regardless of whether or not they received a recorded diagnosis of depression.

Patients with extended use of anxiolytics or hypnotics had the longest duration of antidepressant therapy in the post period (Table 3). Patients with brief post period use of anxiolytics or hypnotics had the shortest duration of antidepressant therapy. This finding was consistent with that of Shields et al., who also found that patients with brief concurrent anxiolytic or hyp- notic therapy had the shortest duration of index therapy, regardless of prescriber specialty. ${ }^{8}$

Collectively, these findings raise some concerns, given the depressogenic nature of anxiolytic/hypnotic agents. As a result, interventions were targeted at educating primary care providers and psychiatrists about the concerns surrounding anxiolytic/ hypnotic use and the need to limit the duration of their use and improve physicians' understanding of depression and its relation to individual anxiety symptoms. Early indications with one MCO suggest the positive impact of these physician interventions. A follow-up study is now underway, and we look forward to reporting the impact of our national improvement interventions in due course.

\section{Conclusion}

The primary purpose of this study was to evaluate the effect of concomitant anxiolytic or hypnotic use on antidepressant duration of therapy among new adult patients receiving pharmacy and medical benefits through a national managed care organization (MCO) and its behavioral health subsidiary. As a result of these findings, interventions were targeted at educating physicians about the need to limit concomitant antidepressant and anxiolytic/hypnotic use and improve their understanding of depression and its relation to individual anxiety symptoms.

\section{REFERENCES}

1. Zajecka JM. New strategies in recognizing and treating refractory depression complicated by anxiety. Medscape 1998.

2. Zajecka JM, Ross JS. Managenent of comorbid anxiety and depression. J Clin Psych 1995; 56(suppl 2): 1.0-13.

3. Keller MB, Hanks DL. Anxicty symptom relief in depression treatment outcomes. J Clin Psych 1995; 56(suppl 6): 22-29.

4. Depression Guideline Panel. Depression in Primary Care: Volume 2. Treatment of Major Depression. Clinical Practice Guideline, Number 5. Rockville, MD. U.S. Department of Health and Human Services, Public Health Service, Agency for Health Care Policy and Research 1993; AHCPR Publication No. 93-0551.

5. Goldberg JF. The treatment of chronic depression: Current strategies and future directions. Medscape Mental Health 1997; 2(6).

6. Drug Facts and Comparisons. St. Louis: Facts and Comparisons, 1997.

7. Brintnall EO, Whitehouse D, Young CH, Way K, Hughes T. Depression diagnoses and associated utilization patterns in a national managed care organization. 1.998 (under review)

8. Shields SA, Gregor KJ, Young CH, James SP. Concomitant use of anxiolytics or hypnotics and the maintenance of initial SSRI therapy. Pharmacotherapy 1998; 28(6): 1298-1303 